\title{
The low temperature oxidation of lithium thin films on HOPG by $\mathrm{O}_{2}$ and $\mathrm{H}_{2} \mathrm{O}$
}

\author{
Steven M. Wulfsberg ${ }^{\text {a }}$, Bruce E. Koel ${ }^{\text {b }}$, Steven L. Bernasek ${ }^{\text {a,* }}$ \\ a Department of Chemistry, Princeton University, Princeton, NJ 08544, USA \\ b Department of Chemical and Biological Engineering, Princeton University, Princeton, NJ 08544, USA
}

\section{A R T I C L E I N F O}

\section{Article history:}

Received 12 November 2015

Received in revised form 11 April 2016

Accepted 11 April 2016

Available online 16 April 2016

\section{Keywords:}

Lithium thin films

Oxidation

Adsorption

Lithiated graphite

\begin{abstract}
A B S T R A C T
Lithiated graphite and lithium thin films have been used in fusion devices. In this environment, lithiated graphite will undergo oxidation by background gases. In order to gain insight into this oxidation process, thin $(<15$ monolayer (ML)) lithium films on highly ordered pyrolytic graphite (HOPG) were exposed to $\mathrm{O}_{2(\mathrm{~g})}$ and $\mathrm{H}_{2} \mathrm{O}_{(\mathrm{g})}$ in an ultra-high vacuum chamber. High resolution electron energy loss spectroscopy (HREELS) was used to identify the surface species formed during $\mathrm{O}_{2(\mathrm{~g})}$ and $\mathrm{H}_{2} \mathrm{O}_{(\mathrm{g})}$ exposure. Auger electron spectroscopy (AES) was used to obtain the relative oxidation rates during $\mathrm{O}_{2(\mathrm{~g})}$ and $\mathrm{H}_{2} \mathrm{O}_{(\mathrm{g})}$ exposure. AES showed that as the lithium film thickness decreased from 15 to 5 to $1 \mathrm{ML}$, the oxidation rate decreased for both $\mathrm{O}_{2(\mathrm{~g})}$ and $\mathrm{H}_{2} \mathrm{O}_{(\mathrm{g})}$. HREELS showed that a $15 \mathrm{ML}$ lithium film was fully oxidized after $9.7 \mathrm{~L}(\mathrm{~L})$ of $\mathrm{O}_{2(\mathrm{~g})}$ exposure and $\mathrm{Li}_{2} \mathrm{O}$ was formed. HREELS also showed that during initial exposure $(<0.5 \mathrm{~L}) \mathrm{H}_{2} \mathrm{O}_{(\mathrm{g})}$, lithium hydride and lithium hydroxide were formed on the surface of a $15 \mathrm{ML}$ lithium film. After $0.5 \mathrm{~L}$ of $\mathrm{H}_{2} \mathrm{O}_{(\mathrm{g})}$ exposure, the $\mathrm{H}_{2} \mathrm{O}_{(\mathrm{g})}$ began to physisorb, and after $15 \mathrm{~L}$ of $\mathrm{H}_{2} \mathrm{O}_{(\mathrm{g})}$ exposure, the $15 \mathrm{ML}$ lithium film was not fully oxidized.
\end{abstract}

(C) 2016 Elsevier B.V. All rights reserved.

\section{Introduction}

The understanding of plasma material interactions and impurity control within fusion devices is a necessary step towards the utilization of fusion energy [1]. Lithium conditioning of the graphite first wall materials in the National Spherical Torus Experiment (NSTX) has been shown to result in a reduction of deuterium recycling and impurities resulting in improved plasma performance [2]. However, a complete understanding of the mechanism by which lithium conditioning improves deuterium recycling and impurity reduction has not yet been achieved.

The first step in understanding how lithium conditioning improves plasma performance is to develop a thorough understanding of how lithium conditioned graphite initially reacts with trace gases present in fusion experiments such as the NSTX. Oxygen containing gas molecules such as $\mathrm{CO}_{(\mathrm{g})}$ and $\mathrm{H}_{2} \mathrm{O}_{(\mathrm{g})}$ readily oxidize metallic lithium and are expected to react with the lithium conditioned graphite plasma facing components of fusion reactors. As a result, it is of interest to characterize these reactions and the chemical composition of the lithium conditioned graphite in plasma facing components in fusion reactors.

Previous work, motivated by plasma material interaction research, has probed how lithium conditioned graphite interacts with deuterium ions. This research has provided information about the oxidation states

\footnotetext{
* Corresponding author.

E-mail address: sberna@princeton.edu (S.L. Bernasek).
}

of the chemical elements on the surface and has shown that oxygen is present on the lithium conditioned graphite surface [3]. However, the assignment of oxide and hydroxide species at the surface has not been fully accomplished. Skinner et al. exposed lithium films to $\mathrm{CO}_{(\mathrm{g})}$, $\mathrm{H}_{2} \mathrm{O}_{(\mathrm{g})}$, and $\mathrm{O}_{2(\mathrm{~g})}$, finding that a $6.8 \mathrm{ML}$ lithium film on polycrystalline molybdenum fully oxidized after $5 \mathrm{~L}$ of $\mathrm{H}_{2} \mathrm{O}_{(\mathrm{g})}$ or $\mathrm{O}_{2(\mathrm{~g})}$ exposure, and that the oxidation rate is four times slower for $\mathrm{CO}_{(\mathrm{g})}$ than for $\mathrm{H}_{2} \mathrm{O}_{(\mathrm{g})}$ and $\mathrm{O}_{2(\mathrm{~g})}$ [4]. Other studies have explored lithium oxidation by exposing

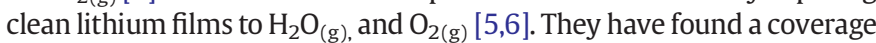
of $1 \mathrm{ML} \mathrm{Li}_{2} \mathrm{O}$ resulted after exposure of the lithium surface to 6 to $7 \mathrm{~L}$ for $\mathrm{O}_{2(\mathrm{~g})}$ and 11 to $12 \mathrm{~L}$ for $\mathrm{H}_{2} \mathrm{O}_{(\mathrm{g})}$. While the work of these authors has provided a solid initial foundation, further work is required to gain a full understanding of the initial oxidation of lithium films, and how a graphite substrate affects the initial lithium oxidation process. Additionally, information about the chemical bonds present at the surface of lithium conditioned graphite remains uncertain and no studies have used vibrational spectroscopy to probe this oxidation process.

This paper presents the results of HREELS studies of thin films of lithium on $\mathrm{HOPG}$ at $100 \mathrm{~K}$ exposed to $\mathrm{H}_{2} \mathrm{O}_{(\mathrm{g})}$ and $\mathrm{O}_{2(\mathrm{~g})}$. It also presents the results of AES studies of the oxidation of lithium conditioned graphite by $\mathrm{H}_{2} \mathrm{O}_{(\mathrm{g})}$ and $\mathrm{O}_{2(\mathrm{~g})}$. Both HREELS and AES are surface sensitive spectroscopic techniques that allow for the identification of chemical bonds and elemental species present on surfaces. When used to study the oxidation of lithium conditioned graphite, a more complete picture of the oxidation process and the substrate effects can be obtained. 


\section{Experimental}

A $10 \mathrm{~mm} \times 10 \mathrm{~mm} \times 1 \mathrm{~mm}$ HOPG grade A sample (Structure Probe, Inc.) was used as the graphite substrate in these experiments. The HOPG was mechanically exfoliated using scotch tape, mounted in the chamber, then annealed to $1000{ }^{\circ} \mathrm{C}$ in ultra-high vacuum (UHV) for $10 \mathrm{~min}$ in order to produce a clean sample. The annealing was repeated prior to each experiment to produce the clean sample as determined by AES.

The experiments were conducted in a stainless steel UHV chamber with a base pressure of $6.2 \times 10^{-11}$ Torr. It includes an introduction chamber, preparation chamber and HREELS chamber. The preparation chamber contains a PHI Model 10-155 cylindrical mirror analyzer Auger electron spectrometer with an electron take-off angle of $42.5^{\circ}$, used to obtain the AES data. There are multiple Varian leak valves for introducing gases to the system, an RBD 04-172 Ion Gun, and a Stanford Research Systems RGA 200 mounted on this chamber. The HREELS chamber houses an LK Technologies ELS 3000, which was used to obtain the HREEL spectra in these experiments.

After the HOPG sample is mounted in the chamber and cleaned, lithium was deposited on the sample using a lithium metal dispenser purchased from SEAS Getters [7]. In order to reduce the amount of lithium intercalating into the HOPG and to study the nascent chemical reactions on the surface, the HOPG sample was cooled to $100 \mathrm{~K}$ using liquid nitrogen before Li deposition. At this temperature, intercalation of Li into the graphite sample is limited, as indicated both by the constant Li AES signal following deposition, and the measured diffusion constant of $\mathrm{Li}$ perpendicular to the basal plane of graphite as determined by Itou, et al. [8]. Based on the measured diffusion constant, it is estimated to take longer than $1 \mathrm{~h}$ for one ML of Li to intercalate into the graphite sample at $100 \mathrm{~K}$. Dosing with oxygen or water, and subsequent spectroscopic analysis takes less than 40 min typically. The amount of lithium deposited on the surface of the HOPG at $100 \mathrm{~K}$ was observed by monitoring the suppression of the carbon Auger electron signal from the HOPG after lithium deposition. One ML of lithium corresponds to $8.3 \times 10^{14}$ atoms $/ \mathrm{cm}^{2}$, based on the density of bulk lithium.

AES kinetic data was collected, in the derivative mode, by using the Auger spectrometer to repeatedly scan over the energy region 480 to $530 \mathrm{eV}$, which contains the oxygen Auger peak at $510 \mathrm{eV}$, during the controlled gas exposure at a pressure of $1 \times 10^{-8}$ Torr. This peak position does not change during the data collection. The Auger spectrometer was scanned at a rate of $5 \mathrm{eV} / \mathrm{s}$, resulting in the acquisition of an Auger

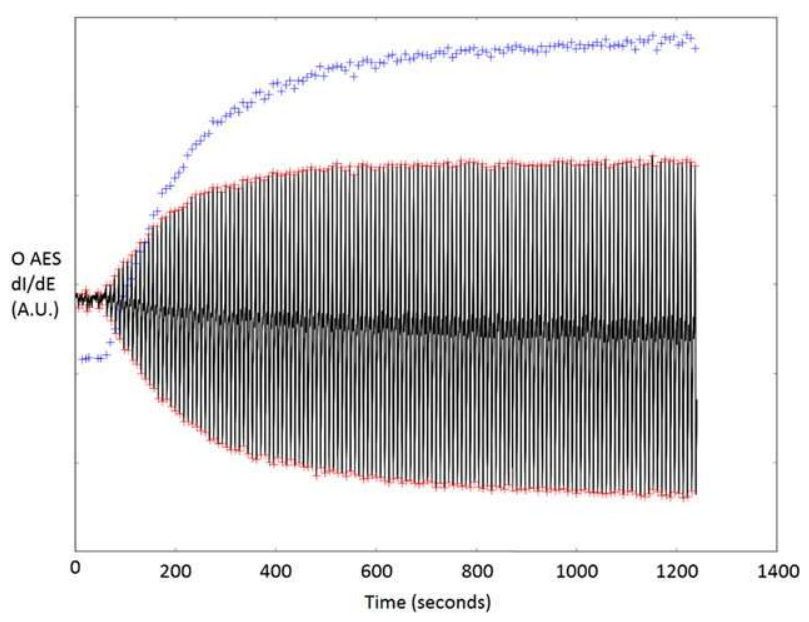

Fig. 1. An example oxygen uptake experiment conducted using AES to continuously scan over 480 to $530 \mathrm{eV}$ in order to monitor the increase in the oxygen Auger electron signal during exposure to $\mathrm{O}_{2}$ at $1 \times 10^{-8}$ Torr. Red data points indicate oxygen peak positions and the blue points represent peak-to-peak oxygen Auger intensity. oxygen peak scan every $10 \mathrm{~s}$. A Python script was written to find the peaks and calculate the peak-to-peak height. An example oxygen uptake spectrum is shown in Fig. 1.

AES was also used to determine the relative concentrations of elements on the surface. The handbook of Auger Electron Spectroscopy and the software AugerScan made by RBD $[9,10]$, provide relative sensitivity factors (RSFs) for primary beam energies of 3, 5, and $10 \mathrm{keV}$ but not $1.5 \mathrm{keV}$. As a result, the RSFs were adjusted using equations for the ionization cross-section [11] and the backscatter correction factor [12]. More information about this correction procedure can be found in the Supplementary Information.

\section{Results and discussion}

\subsection{Auger measurements of Li deposition}

AES was used to follow the suppression of the HOPG carbon Auger electron signal during lithium deposition. This data is presented below in Fig. 2 along with plots from theoretical models describing various common thin film growth modes.

The data in red in Fig. 2 represents actual data collected during lithium deposition using the Saes alkali metal dispenser (AMD). The SAES Getters AMD is capable of producing a well controlled and constant deposition rate [12]. Therefore, the deposition time is directly proportional to the amount of lithium being deposited on the surface. The four other curves in Fig. 2 show what the HOPG carbon Auger electron intensity decrease would be as a function of deposition time if the lithium film grows according to one of four common thermodynamic growth modes. These growth modes are the Volmer-Weber (VW), Stranski-Krastanov (SK), FrankVan der Merwe (FM), and simultaneous multilayer (SM). All four of these growth modes assume sufficient mobility of Li at the deposition temperature, that the growth is not kinetically limited over the time of the measurement. Both the VW and SK modes involve the deposited lithium atoms, coalescing and growing as islands. The difference between the VW and SK modes is that in the SK mode, an atomically smooth, uniform, and complete initial ML is first grown followed by island growth, but in the VW mode, island growth occurs from the beginning without the formation of an atomically smooth, uniform, and complete initial ML. The FM mode involves a layer-by-layer growth, where the deposited

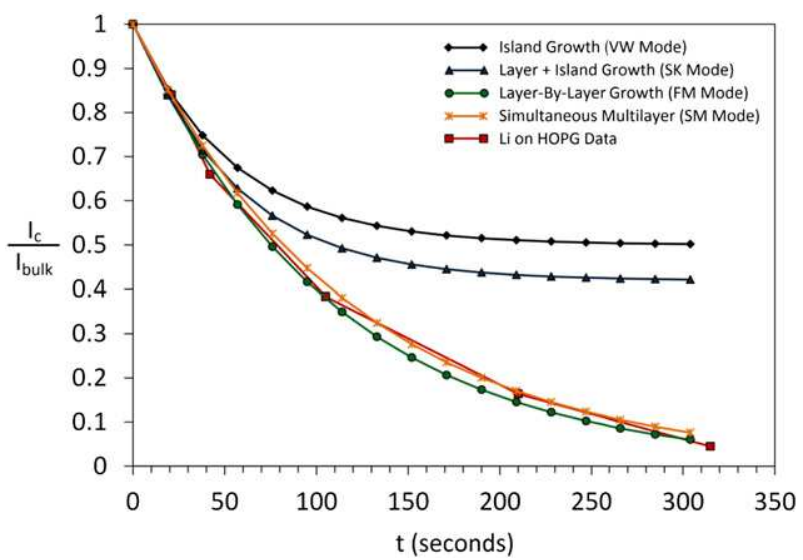

Fig. 2. HOPG carbon AES signal suppression versus lithium deposition time. $\mathrm{I}_{\mathrm{C}_{m}}$ is the carbon AES signal from clean HOPG and $\mathrm{I}_{\mathrm{C}}$ is the carbon signal after lithium deposition. The Li on HOPG data (red) is the experimental data collected during lithium deposition at $100 \mathrm{~K}$. The SM (simultaneous multilayer) mode, the FM (Frank-Van der Merwe) mode, the SK (Stranski-Krastanov) mode, and the VW (Volmer-Weber) mode are theoretical data points calculated from models describing these modes. The lithium deposition rate is $1 \mathrm{ML}$ of Li per $19 \mathrm{~s}$ and the percentage of island coverage on the surface is chosen to be 50 . 
lithium atoms form atomically smooth, uniform, and complete monolayers before the subsequent layer begins to form in the same fashion. The SM mode results from deposited atoms sticking to the surface where they initially land. The SM mode can best be described as stacks of lithium atoms covering the surface. The heights of the lithium atom stacks are expected to obey a Poisson distribution centered on the average thickness of the lithium film.

It was not possible to predict by which of these growth modes lithium deposition would occur, nor has any previous research determined the growth mode of lithium on HOPG. Therefore, to obtain an understanding of how the lithium thin films grew on the HOPG surface, it was necessary to compare the actual lithium deposition data to the models describing the VW, SK, FM, and SM growth modes. The shape of the plot of carbon Auger electron intensity decrease versus deposition time resulting from the VW, SK, FM, and SM models, will depend on the deposition rate and the percentage of island coverage on the surface. The deposition rate, in monolayers (ML) of lithium per second, and the percentage of island coverage on the surface were varied from $1 \mathrm{ML}$ per $10 \mathrm{~s}$ to $1 \mathrm{ML}$ per $30 \mathrm{~s}$ and from $25 \%$ to $75 \%$ island coverage in order to see which growth mode fit the actual data the best. Deposition rates less than $1 \mathrm{ML}$ per $15 \mathrm{~s}$ and more than $1 \mathrm{ML}$ per $25 \mathrm{~s}$ resulted in curves that decreased too rapidly and too slowly, respectively, and did not fit the actual deposition data. Additionally, the actual data did not fit the two VW or SK models involving island growth unless the percentage of island coverage was greater than 95, and at this limit the VW and SK modes become the FM mode. Therefore, it was concluded that the lithium was not growing according to either the VW or SK modes. However, as Fig. 2 shows, the actual data closely fit the FM and SM growth modes. When the lithium deposition rate was chosen to be $1 \mathrm{ML}$ per $20 \mathrm{~s}$, the actual data closely matched the FM mode, and when the lithium deposition rate was chosen to be $1 \mathrm{ML}$ per $18 \mathrm{~s}$, the actual data closely matched the SM mode. The SM and FM modes produce very similar curves in general, as seen in Fig. 2, and with the data collected during the lithium deposition, it was not possible to distinguish between the FM and SM growth modes. As a result, a lithium deposition rate of $1 \mathrm{ML}$ per $19 \mathrm{~s}$ was chosen to represent the actual rate of lithium deposition used in the following experiments. This rate of $1 \mathrm{ML}$ per $19 \mathrm{~s}$ was used to deposit controlled and calibrated amounts of lithium on HOPG during the experiments reported here.

Eq. (1) describes the layer-by-layer FM growth mode used in the previous discussion.

$\mathrm{I}_{\mathrm{C}(\mathrm{HOPG})}=\mathrm{I}_{\mathrm{C}(\mathrm{HOPG})_{\infty}} \exp \left[-\frac{\mathrm{x}}{\cos (\phi) \lambda_{\mathrm{Li}(272 \mathrm{eV})}}\right]$

where $\mathrm{I}_{\mathrm{C}(\mathrm{HOPG})_{\infty}}$ is the intensity of the carbon Auger signal from clean thick HOPG, $\phi$ is the takeoff angle of the electrons from the surface relative to the surface normal, $\lambda_{\mathrm{Li}(272 \mathrm{eV})}$ is the inelastic mean free path (IMFP) of the carbon Auger electron through the lithium film, and $\mathrm{x}$ is the thickness of the lithium overlayer in $\AA$. The value for $\lambda_{\mathrm{Li}}(272 \mathrm{eV})$ was taken from the NIST electron IMFP database [13].

\subsection{Thin Li films on $\mathrm{HOPG}$ exposed to $\mathrm{O}_{2}$}

\subsection{1. $\mathrm{O}_{2}$ auger electron spectroscopy oxygen uptake experiments}

Auger electron spectroscopy (AES) was used to follow the oxygen uptake of 1,5 and $15 \mathrm{ML}$ lithium films on highly ordered pyrolytic graphite (HOPG) at $100 \mathrm{~K}$ during $\mathrm{O}_{2(\mathrm{~g})}$ exposure at a constant pressure of $1 \times 10^{-8}$ Torr. These oxygen uptake curves are shown in Fig. 3 .

From Fig. 3, it can be seen that as the initial lithium film thickness increases from 1 to 5 to $15 \mathrm{ML}$, the oxygen uptake curves saturate at higher oxygen AES signal intensities and at longer $\mathrm{O}_{2(\mathrm{~g})}$ exposures. Additionally, the initial slopes of the oxygen uptake curves decrease from 15 to 5 to $1 \mathrm{ML}$ initial Li film thickness. These initial slopes provide

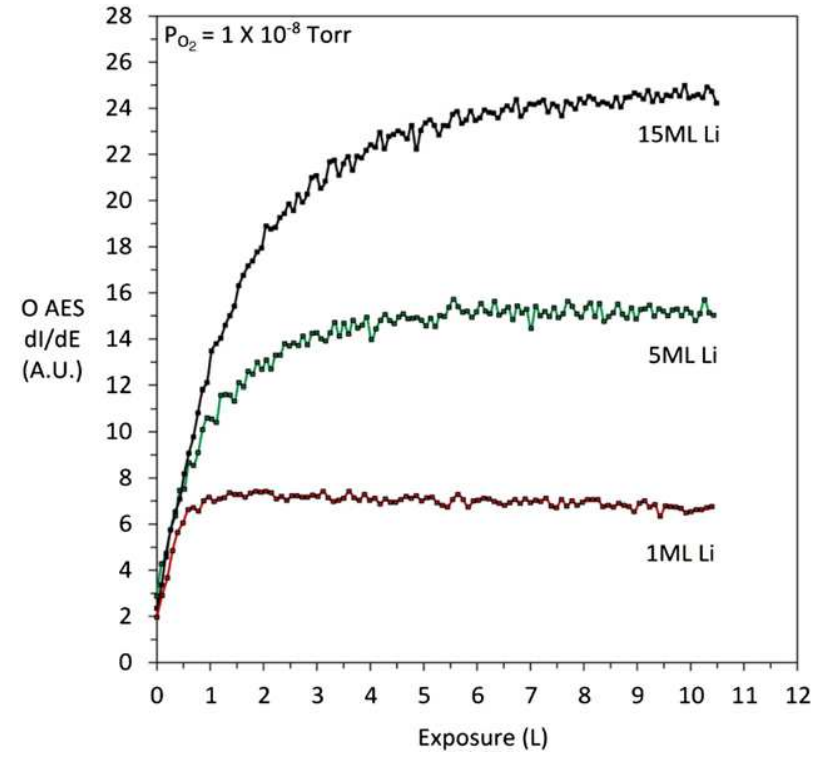

Fig. 3. $\mathrm{O}_{2(\mathrm{~g})}$ AES oxygen uptake curves for 1 (red), 5 (green), and 15 (black) ML lithium films on HOPG at $100 \mathrm{~K}$. The $\mathrm{O}_{2(\mathrm{~g})}$ partial pressure was $1 \times 10^{-8}$ Torr during the oxygen uptake experiments.

the initial sticking coefficients for $\mathrm{O}_{2(\mathrm{~g})}$ on clean lithium films and are presented in Table 1.

In order to determine why the oxygen uptake curve for the $15 \mathrm{ML}$ lithium film saturates after approximately $9.5 \mathrm{~L}$ of $\mathrm{O}_{2(\mathrm{~g})}$ exposure, three scenarios can be considered. These three scenarios all assume that $\mathrm{O}_{2(\mathrm{~g})}$ reacts with the lithium films to form $\mathrm{Li}_{2} \mathrm{O}$. The first scenario suggests that the $\mathrm{Li}_{2} \mathrm{O}$ film has grown beyond the AES probe depth. The probe depth for AES is defined as three times the IMFP of an oxygen Auger electron. The IMFP of an oxygen Auger electron is $16.2 \AA$ in $\mathrm{Li}_{2} \mathrm{O}$, giving a probe depth of approximately $48.6 \AA$. Again, all IMFP values are taken from the NIST electron IMFP database [13]. A 15 ML lithium film contains approximately enough lithium to produce $6.7 \mathrm{ML}$ of $\mathrm{Li}_{2} \mathrm{O}$ if the lithium fully reacts to form $\mathrm{Li}_{2} \mathrm{O}$, assuming that the $15 \mathrm{ML}$ lithium film has the density of lithium metal. A 6.7 ML film of $\mathrm{Li}_{2} \mathrm{O}$ has a thickness of only $18.4 \AA$. This value is less than half of the AES probe depth. As a result, the AES oxygen uptake curve saturation is not a result of the $\mathrm{Li}_{2} \mathrm{O}$ film growing beyond the AES probe depth.

The second scenario proposes that the $15 \mathrm{ML}$ lithium film has passivated and $\mathrm{O}_{2}$ can no longer diffuse through the lithium oxide film and oxidize the underlying lithium metal. AES survey scans taken after the $\mathrm{O}_{2(\mathrm{~g})}$ oxygen uptake experiment show that there is no lithium metal Auger electron signal, suggesting that there is no unreacted lithium metal on the surface. Metallic Li has an Auger electron peak at $52 \mathrm{eV}$ and $40 \mathrm{eV}[14,15]$ Therefore, the saturation level in Fig. 3, above, is not the result of the lithium film passivation, leaving the bottom-most lithium monolayers unreacted.

Table 1

Sticking coefficients determined by linear regression fits to the initial slope data for oxygen AES signal vs $\mathrm{O}_{2}$ exposure curves from Fig. 3. The sticking coefficients have been normalized to the sticking coefficient from the AES oxygen uptake curve for the 15 ML lithium film.

\begin{tabular}{llll}
\hline & $15 \mathrm{ML} \mathrm{Li}$ & $5 \mathrm{ML} \mathrm{Li}$ & $1 \mathrm{ML} \mathrm{Li}$ \\
\hline Relative initial sticking coefficients & $1.00 \pm 0.09$ & $0.82 \pm 0.07$ & $0.78 \pm 0.06$
\end{tabular}


The most likely scenario to explain the 15 ML lithium oxygen uptake curve saturation is that the whole $15 \mathrm{ML}$ lithium film has been oxidized by the $\mathrm{O}_{2(\mathrm{~g})}$. With the saturation value from the oxygen uptake curve of the $15 \mathrm{ML}$ lithium film corresponding to the AES oxygen signal intensity from a $6.7 \mathrm{ML} \mathrm{Li}_{2} \mathrm{O}$ film (since a $15 \mathrm{ML}$ lithium film contains approximately enough lithium to produce $6.7 \mathrm{ML}$ of $\mathrm{Li}_{2} \mathrm{O}$ ) and using a layer by layer oxide growth model, it is possible to calculate the AES oxygen signal intensity corresponding to the formation of the $1 \mathrm{st}, 2 \mathrm{nd}, 4 \mathrm{th}$, and 6.7th MLs of $\mathrm{Li}_{2} \mathrm{O}$ using Eq. (2) below:

$$
\frac{\mathrm{I}_{6.7 \mathrm{ML}}}{\mathrm{I}_{\mathrm{nML}}}=\frac{1-\exp \left[-\frac{6.7 \mathrm{ML}}{\cos (\phi) \lambda_{\mathrm{Li}_{2} \mathrm{O}(510 \mathrm{eV})}}\right]}{1-\exp \left[-\frac{\mathrm{nML}}{\cos (\phi) \lambda_{\mathrm{Li}_{2} \mathrm{O}(510 \mathrm{eV})}}\right]}
$$

where $\mathrm{I}_{6.7 \mathrm{ML}}$ is the oxygen AES signal corresponding to $6.7 \mathrm{ML}$ of $\mathrm{Li}_{2} \mathrm{O}$; $\mathrm{I}_{\mathrm{nML}}$ is the AES oxygen signal intensity corresponding to the nth ML of $\mathrm{Li}_{2} \mathrm{O} ; \phi$ is the takeoff angle of the electron from the surface relative to the surface normal; and $\lambda_{\mathrm{Li}_{2} \mathrm{O}(510 \mathrm{eV})}$ is the IMFP, in units of $\mathrm{Li}_{2} \mathrm{O}$ MLs, of the oxygen Auger electron through the $\mathrm{Li}_{2} \mathrm{O}$ layer. Using Eq. (2) and the data from Fig. 3, the exposures at which the formation of 1, 2, 4, and $6.7 \mathrm{ML}$ of $\mathrm{Li}_{2} \mathrm{O}$ occur can be calculated. These values are presented in Table 2, below.

Under the conditions of these experiments, it can be seen that $1 \mathrm{ML}$ of $\mathrm{Li}_{2} \mathrm{O}$ is formed after just $0.36 \mathrm{~L}$ of $\mathrm{O}_{2(\mathrm{~g})}$ exposure and the $15 \mathrm{ML}$ of lithium film is fully oxidized after $9.70 \mathrm{~L}$ of $\mathrm{O}_{2(\mathrm{~g})}$ exposure.

As mentioned above, Fig. 3 shows a decrease in the initial sticking coefficients as the initial lithium film thickness decreases from 15 to 5 to $1 \mathrm{ML}$. These initial sticking coefficient values are presented in Table 1 , above. Previous studies have shown that lithium transfers its valance electron to the conduction band of graphite [14]. This electron transfer can make the lithium less reactive towards electronegative molecules such as $\mathrm{O}_{2(\mathrm{~g})}$. The effect of this electron transfer process would be strongest for the lithium monolayer closest to the HOPG substrate, and this trend is seen in the data as a decrease in the initial sticking coefficients as the lithium film gets thinner from 15 to 5 to $1 \mathrm{ML}$. However, this decrease in the initial sticking coefficient could also be the result of an SM growth mode of the lithium thin film on graphite, since 5 and 15 ML lithium films grown according the SM growth mode would likely exhibit kinks and step edges, providing sites of relatively high reactivity and resulting in a higher initial sticking coefficient than the case for a $1 \mathrm{ML}$ lithium film.

\subsection{2. $\mathrm{O}_{2}$ HREELS}

In addition to AES, HREELS was used to follow the oxidation by $\mathrm{O}_{2(\mathrm{~g})}$ of a $15 \mathrm{ML}$ Li film on HOPG at $100 \mathrm{~K}$. The results of these experiments are presented in Fig. 4.

HREEL spectra were taken at $0.25,0.5,0.75,1,3$, and $5 \mathrm{~L}$ of sequential $\mathrm{O}_{2(\mathrm{~g})}$ exposure. At $0.25 \mathrm{~L} \mathrm{O}_{2(\mathrm{~g})}$ exposure, a small broad peak is seen at $600 \mathrm{~cm}^{-1}$. As the $\mathrm{O}_{2(\mathrm{~g})}$ exposure increases from 0.25 to $5 \mathrm{~L}$, this peak gradually shifts to $705 \mathrm{~cm}^{-1}$ and increases in intensity, suggesting this peak is a result of the reaction between $\mathrm{O}_{2(\mathrm{~g})}$ and lithium. Additionally, in the HREEL spectrum taken after $0.5 \mathrm{~L}$ of $\mathrm{O}_{2(\mathrm{~g})}$, the lack of a peak at $3700 \mathrm{~cm}^{-1}$ indicates the peak at $705 \mathrm{~cm}^{-1}$ is not the result of $\mathrm{H}_{2} \mathrm{O}_{(\mathrm{g})}$ contamination from the vacuum chamber's background gas forming $\mathrm{LiOH}$, which has a $v(\mathrm{O}-\mathrm{H})$ peak around $3700 \mathrm{~cm}^{-1}$. Rather, this peak at $705 \mathrm{~cm}^{-1}$ must be a result of the interaction between $\mathrm{O}_{2(\mathrm{~g})}$ and the

Table 2

$\mathrm{O}_{2(\mathrm{~g})}$ exposures at which $1,2,4$ and $6.7 \mathrm{ML}$ of $\mathrm{Li}_{2} \mathrm{O}$ are formed.

\begin{tabular}{lllll}
\hline & $1 \mathrm{ML} \mathrm{Li}_{2} \mathrm{O}$ & $2 \mathrm{ML} \mathrm{Li}_{2} \mathrm{O}$ & $4 \mathrm{ML} \mathrm{Li}_{2} \mathrm{O}$ & $6.7 \mathrm{ML} \mathrm{Li}_{2} \mathrm{O}$ \\
\hline $\mathrm{O}_{2}$ exposure (L) (l(L) & 0.36 & 0.82 & 2.11 & 9.70 \\
\hline
\end{tabular}

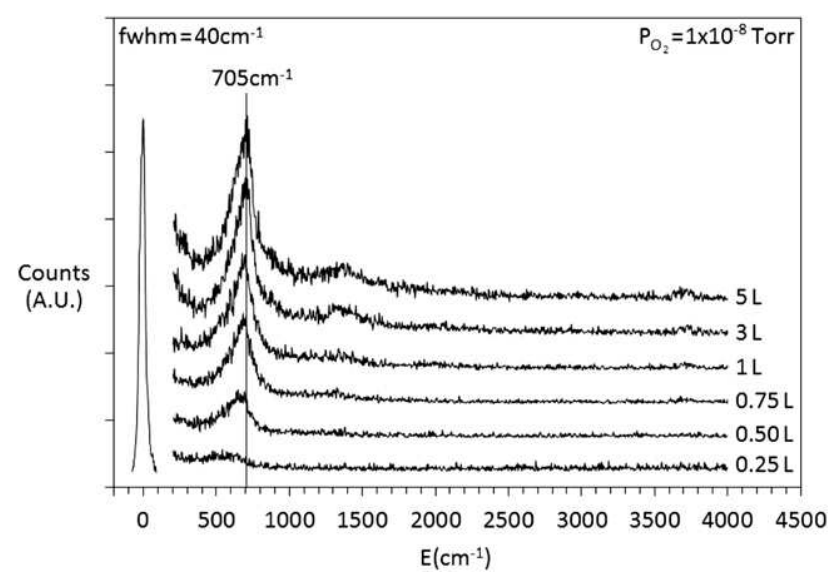

Fig. 4. HREEL spectra of a $15 \mathrm{ML}$ lithium film on $\mathrm{HOPG}$ at $100 \mathrm{~K}$ after $0.25,0.50,0.75,1.00$, 3.00 , and $5.00 \mathrm{~L}$ of $\mathrm{O}_{2(\mathrm{~g})}$ exposure. $\mathrm{O}_{2(\mathrm{~g})}$ partial pressures used during these exposures were $1 \times 10^{-8}$ Torr. The typical resolution and elastic peak intensity of the spectra was $40 \mathrm{~cm}^{-1}$ fwhm and $20,000 \mathrm{cts} / \mathrm{s}$.

lithium film. The absence of a peak between 850 and $1200 \mathrm{~cm}^{-1}$, due to the presence of molecular $\mathrm{O}_{2(\mathrm{~g})}$ adsorbed on the surface, suggests the $\mathrm{O}_{2(\mathrm{~g})}$ dissociates upon adsorption on the lithium surface $[15,16]$. Off-specular HREEL spectra also do not show a peak between 850 and $1200 \mathrm{~cm}^{-1}$. This confirms that the $\mathrm{O}_{2(\mathrm{~g})}$ dissociates upon adsorption on the lithium surface. There is also a small peak at $1400 \mathrm{~cm}^{-1}$. This peak is the result of a double scattering event for the peak at $700 \mathrm{~cm}^{-1}$. After higher exposures (above $3 \mathrm{~L} \mathrm{O}_{2(\mathrm{~g})}$ ), another peak is seen around $3700 \mathrm{~cm}^{-1}$ in the HREELS data. After long exposure, background $\mathrm{H}_{2} \mathrm{O}_{(\mathrm{g})}$ exposure is large enough to result in the formation of $\mathrm{LiOH}$. This peak is the result of the lithium oxide reacting with trace amounts of $\mathrm{H}_{2} \mathrm{O}_{(\mathrm{g})}$ in the vacuum chamber to form $\mathrm{LiOH}$. Previous reflection infrared spectroscopic studies have shown that $\mathrm{Li}_{2} \mathrm{O}$ exhibits a longitudinal phonon mode at $737 \mathrm{~cm}^{-1}$ [17]. The $705 \mathrm{~cm}^{-1}$ peak seen is Fig. 3 is most likely the result of the phonon mode of $\mathrm{Li}_{2} \mathrm{O}$, suggesting the $15 \mathrm{ML}$ lithium film reacts with incident $\mathrm{O}_{2(\mathrm{~g})}$ to form $\mathrm{Li}_{2} \mathrm{O}$.

HREEL spectra were recorded immediately after the AES oxygen uptake experiments for the 1,5, and $15 \mathrm{ML}$ Li films on HOPG at $100 \mathrm{~K}$ exposed to $15 \mathrm{~L} \mathrm{O}_{2(\mathrm{~g})}$. These spectra are shown in Fig. 5.

Fig. 5 shows that as the initial lithium film thickness increases, which results in the formation of thicker $\mathrm{Li}_{2} \mathrm{O}$ films, the peak at $600 \mathrm{~cm}^{-1}$ grows in intensity and shifts towards a higher energy of $700 \mathrm{~cm}^{-1}$. Again, $\mathrm{Li}_{2} \mathrm{O}$ is known to have a longitudinal phonon mode at $737 \mathrm{~cm}^{-1}$ [17]. Another feature seen in Fig. 5 is $v(0-H)$ at $3700 \mathrm{~cm}^{-1}$. This feature suggests that the $\mathrm{Li}_{2} \mathrm{O}$ film experiences terminal hydroxylation for lithium film thicknesses of 5 ML lithium or larger. Again, the

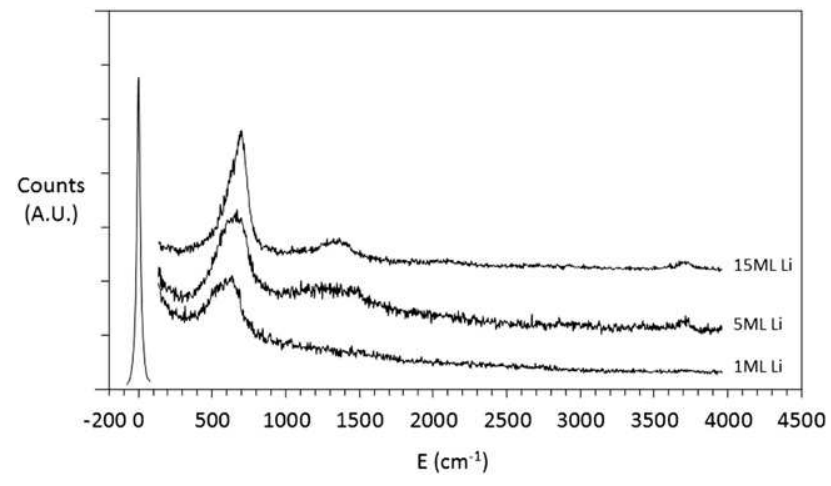

Fig. 5. HREEL spectra taken after the $15 \mathrm{~L}$ of $\mathrm{O}_{2(\mathrm{~g})}$ exposure from the AES oxygen uptake experiments for 1,5 , and $15 \mathrm{ML}$ lithium films on HOPG at $100 \mathrm{~K}$. The typical resolution and elastic peak intensity of the spectra was $35 \mathrm{~cm}^{-1} \mathrm{fwhm}$ and 50,000 cts/s. 
peak around $1400 \mathrm{~cm}^{-1}$ seen in the HREEL spectrum from an oxidized $15 \mathrm{ML}$ lithium film, is attributed to a double scattering event related to the peak around $700 \mathrm{~cm}^{-1}$. The data suggests that as the $\mathrm{Li}_{2} \mathrm{O}$ film increases in thickness, the HREEL spectra corresponds to spectra consistent with $\mathrm{Li}_{2} \mathrm{O}$. Also, as the oxidized lithium film thickness increases, it becomes more susceptible to terminal hydroxylation.

Auger spectroscopy survey scans were taken after the AES oxygen uptake experiments for the 1,5, and 15 ML lithium films on HOPG at $100 \mathrm{~K}$ exposed to $15 \mathrm{~L} \mathrm{O}_{2(\mathrm{~g})}$. Using Auger sensitivity factors, these scans allow for the calculation of the ratios of the atomic concentrations of lithium to oxygen, assuming a homogenous film composition. These ratios are presented in Table 3, below.

Table 3 shows that as the initial lithium film thickness increases, the ratio of lithium to oxygen decreases and approaches 2 to 1 , the ratio expected for $\mathrm{Li}_{2} \mathrm{O}$. This trend in the AES lithium to oxygen ratios, combined with the trends seen in the HREELS data, suggests that as the oxidized lithium film thickness increases, it exhibits properties that are characteristic of $\mathrm{Li}_{2} \mathrm{O}$ and grows into bulk $\mathrm{Li}_{2} \mathrm{O}$.

\subsection{Thin Li films on HOPG Exposed to $\mathrm{H}_{2} \mathrm{O}$}

\subsection{1. $\mathrm{H}_{2} \mathrm{O}$ exposure oxygen uptake experiments}

AES was used to follow the oxygen uptake by 1,5 and $15 \mathrm{ML}$ lithium films on highly ordered pyrolytic graphite (HOPG) at $100 \mathrm{~K}$ during $\mathrm{H}_{2} \mathrm{O}_{(\mathrm{g})}$ exposure at a constant pressure of $1 \times 10^{-8}$ Torr. These AES oxygen uptake curves are shown in Fig. 6.

From Fig. 6, it can be seen that as the initial lithium film thickness increases from 1 to 5 to $15 \mathrm{ML}$, the oxygen uptake curves saturate at higher oxygen $\mathrm{AES}$ intensities and at longer $\mathrm{H}_{2} \mathrm{O}_{(\mathrm{g})}$ exposures. Additionally, the initial slopes, from 0 to $0.5 \mathrm{~L}$ exposure, obtained by linear regression fits of the initial exposure data from these oxygen uptake curves, decrease from 15 to 5 to $1 \mathrm{ML}$, as can be seen in Table 4 , below. This decrease in the initial sticking coefficient for $\mathrm{H}_{2} \mathrm{O}_{(\mathrm{g})}$ is very comparable to the decrease seen for $\mathrm{O}_{2(\mathrm{~g})}$, which decreased from 1.0 to 0.78 as the initial lithium film thickness increased.

Control experiments were conducted to identify any electron beam effects during the AES oxygen uptake experiments. It was found that turning off the electron beam at any point between 0 and $5 \mathrm{~L}$ of $\mathrm{H}_{2} \mathrm{O}_{(\mathrm{g})}$ exposure during the AES oxygen uptake experiments did not affect the oxygen uptake curve. However turning off the electron beam after $5 \mathrm{~L}$ of $\mathrm{H}_{2} \mathrm{O}_{(\mathrm{g})}$ exposure during the AES oxygen uptake experiments did affect the oxygen uptake curve by allowing $\mathrm{H}_{2} \mathrm{O}_{(\mathrm{g})}$ to condense on the surface and increasing the oxygen AES signal. This indicates that the electron beam stimulated the desorption of multilayer $\mathrm{H}_{2} \mathrm{O}_{(\mathrm{g})}$. This condition also explains why the oxygen uptakes curves for $\mathrm{H}_{2} \mathrm{O}_{(\mathrm{g})}$ exposure saturate, rather than continue to increase from $\mathrm{H}_{2} \mathrm{O}_{(\mathrm{g})}$ condensation. However, in spite of the electron stimulated desorption, the saturation values increase with increasing initial lithium thickness. This indicates that an initial $15 \mathrm{ML}$ lithium film is able to react with more $\mathrm{H}_{2} \mathrm{O}_{(\mathrm{g})}$ than a $5 \mathrm{ML}$ lithium film and a $5 \mathrm{ML}$ lithium film is able to react with more $\mathrm{H}_{2} \mathrm{O}_{(\mathrm{g})}$ than a $1 \mathrm{ML}$ lithium film. Additionally, AES survey scans taken after the oxygen uptake measurements show a small lithium metal peak for the $15 \mathrm{ML}$ lithium film indicating that not all the lithium has oxidized, unlike the analogous $\mathrm{O}_{2(\mathrm{~g})}$ oxygen uptake experiments that show no lithium metal AES peaks.

When the relative initial sticking coefficient of the $\mathrm{O}_{2(\mathrm{~g})}$ oxygen uptake curve of a $15 \mathrm{ML}$ lithium film is compared to the $\mathrm{H}_{2} \mathrm{O}_{(\mathrm{g})}$ oxygen

Table 3

Ratios of lithium to oxygen atoms in the 1, 5, and 15 ML lithium films on HOPG at $100 \mathrm{~K}$ after the $15 \mathrm{~L}$ of $\mathrm{O}_{2(\mathrm{~g})}$ exposure from the AES oxygen uptake experiments.

\begin{tabular}{cll}
\hline Atomic Conc. & $\mathrm{Li}$ & $\mathrm{O}$ \\
\hline $1 \mathrm{ML} \mathrm{Li}$ & 3.6 & 1.0 \\
$5 \mathrm{ML} \mathrm{Li}$ & 2.7 & 1.0 \\
$15 \mathrm{ML} \mathrm{Li}$ & 2.4 & 1.0 \\
\hline
\end{tabular}

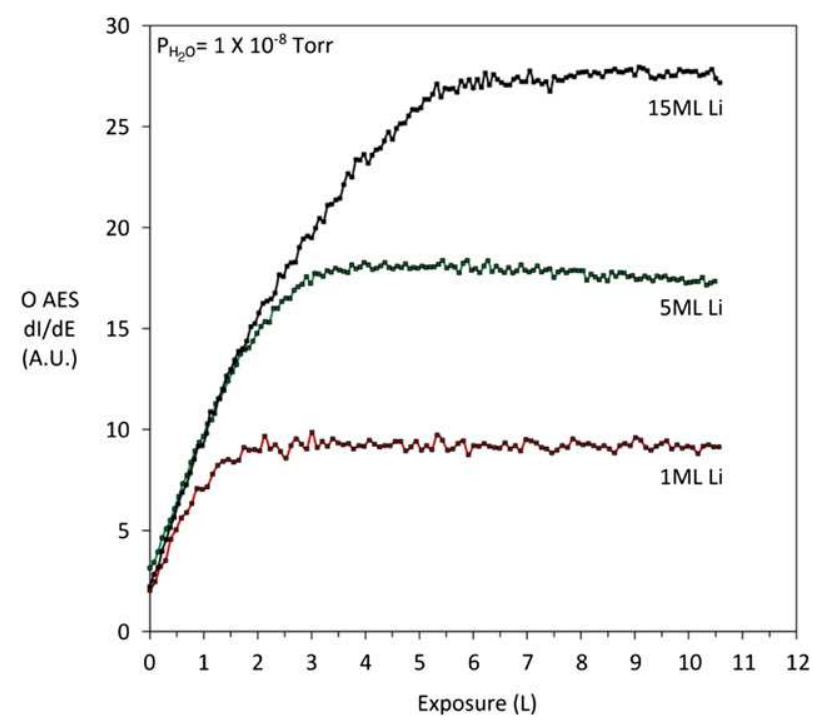

Fig. 6. $\mathrm{H}_{2} \mathrm{O}_{(\mathrm{g})}$ AES oxygen uptake curves for 1 (red), 5 (blue), and 15 (black) ML lithium films on HOPG at $100 \mathrm{~K}$ during $\mathrm{H}_{2} \mathrm{O}$ exposure. The $\mathrm{H}_{2} \mathrm{O}_{(\mathrm{g})}$ partial pressure was $1 \times 10^{-8}$ Torr during the oxygen uptake experiments.

uptake curve of a $15 \mathrm{ML}$ lithium film, it is found that $\mathrm{O}_{2(\mathrm{~g})}$ has a relative initial sticking coefficient of 0.95 and $\mathrm{H}_{2} \mathrm{O}_{(\mathrm{g})}$ has a relative initial sticking coefficient of 1.00. These values have been normalized for the oxygen stoichiometry of the adsorbing gases. These relative sticking coefficients of $\mathrm{O}_{2(\mathrm{~g})}$ and $\mathrm{H}_{2} \mathrm{O}_{(\mathrm{g})}$ are in agreement with those found in previous research work [5].

\subsection{2. $\mathrm{H}_{2} \mathrm{O}$ HREELS}

In addition to AES, HREELS was used to follow the oxidation by $\mathrm{H}_{2} \mathrm{O}_{(\mathrm{g})}$ of a $15 \mathrm{ML}$ lithium film on HOPG at $100 \mathrm{~K}$. The results of these experiments are presented in Fig. 7.

The HREEL spectrum taken after $0.0625 \mathrm{~L} \mathrm{H}_{2} \mathrm{O}_{(\mathrm{g})}$ shows peaks at 600 and $3688 \mathrm{~cm}^{-1}$. These peaks correspond to the $v(\mathrm{Li}-\mathrm{OH})$ vibration and the $v(\mathrm{LiO}-\mathrm{H})$ vibration, respectively [18]. The spectrum taken after $0.5 \mathrm{~L}$ of $\mathrm{H}_{2} \mathrm{O}_{(\mathrm{g})}$ exposure, shows new peaks begin to grow in at $220,800,1600$, and $3400 \mathrm{~cm}^{-1}$, these peaks correspond to the frustrated translation, frustrated rotation,

$\delta(\mathrm{O}-\mathrm{H})$, and $\mathrm{H}$-bonded $v(\mathrm{O}-\mathrm{H})$ vibrations of adsorbed $\mathrm{H}_{2} \mathrm{O}_{(\mathrm{g})}[19]$. Fig. 6 shows that $\mathrm{H}_{2} \mathrm{O}_{(\mathrm{g})}$, at a pressure of $1 \times 10^{-8}$ Torr, will begin to convert a $15 \mathrm{ML}$ lithium film on HOPG at $100 \mathrm{~K}$ into LiOH. However, after approximately $0.5 \mathrm{~L}$ of $\mathrm{H}_{2} \mathrm{O}_{(\mathrm{g})}$ exposure, $\mathrm{H}_{2} \mathrm{O}_{(\mathrm{g})}$ begins to physisorb on the surface indicating that the LiOH layer formed has passivated the surface, slowing down and possibly preventing further oxidation. This observation is in agreement with Zavadil et al. [5] who found that after exposing bulk clean lithium to $66 \mathrm{~L} \mathrm{H}_{2} \mathrm{O}_{(g)}$ at $143 \mathrm{~K}$, there were XPS peaks in the oxygen region corresponding to hydroxide and condensed $\mathrm{H}_{2} \mathrm{O}_{(\mathrm{g})}$. However, over the course of two hours after the $66 \mathrm{~L} \mathrm{H}_{2} \mathrm{O}_{(\mathrm{g})}$ exposure, there was no evidence for further oxidation of the lithium by the condensed $\mathrm{H}_{2} \mathrm{O}_{(\mathrm{g})}$.

In Fig. 7, there is one peak that is not readily assigned. This is the peak located at $952 \mathrm{~cm}^{-1}$ and seen in the HREEL spectra taken after
Table 4

Sticking coefficients determined by linear regression fits to the initial slope data for oxygen AES signal vs water exposure curves from Fig. 6 . The sticking coefficients have been normalized to the sticking coefficient from the AES oxygen uptake curve for the $15 \mathrm{ML}$ lithium film.

\begin{tabular}{llll}
\hline & $15 \mathrm{ML} \mathrm{Li}$ & $5 \mathrm{ML} \mathrm{Li}$ & $1 \mathrm{ML} \mathrm{Li}$ \\
\hline Relative Initial Sticking Coefficients & $1.00 \pm 0.09$ & $0.86 \pm 0.07$ & $0.81 \pm 0.07$
\end{tabular}




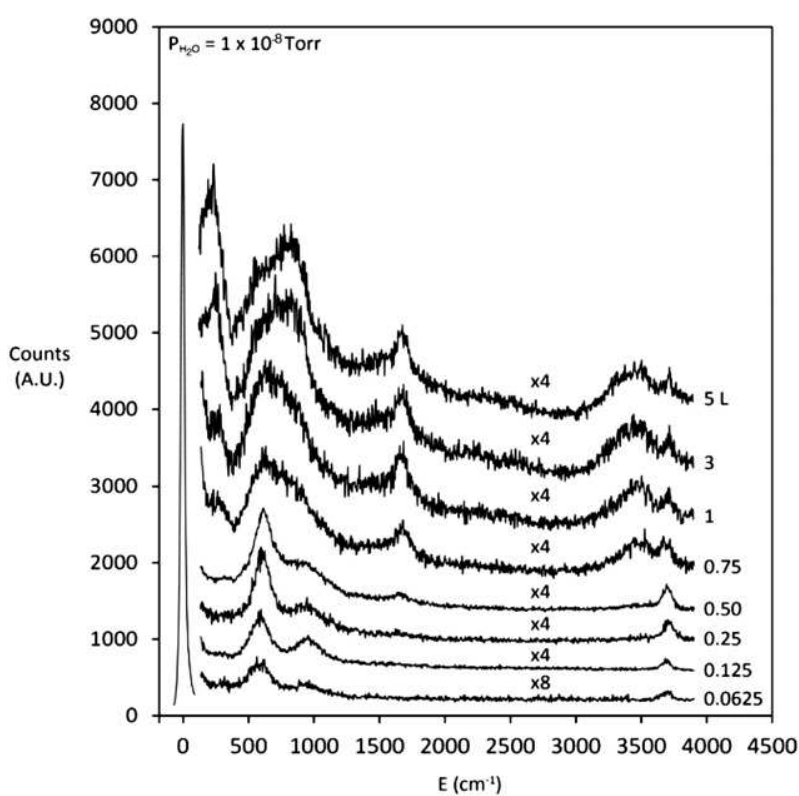

Fig. 7. HREEL spectra of a $15 \mathrm{ML}$ lithium film on HOPG at $100 \mathrm{~K}$ after $0.0625,0.125,0.25$, $0.50,0.75,1.00,3.00$, and $5.00 \mathrm{~L}$ of $\mathrm{H}_{2} \mathrm{O}_{(\mathrm{g})}$ exposure. $\mathrm{H}_{2} \mathrm{O}_{(\mathrm{g})}$ partial pressure used during these exposures was $1 \times 10^{-8}$ Torr. The typical resolution and elastic peak intensity of the spectra was $40 \mathrm{~cm}^{-1} \mathrm{fwhm}$ and $20,000 \mathrm{cts} / \mathrm{s}$.

0.0625 to $0.50 \mathrm{~L} \mathrm{H}_{2} \mathrm{O}$ exposures. Hydrogen and deuterium isotopic substitution experiments were conducted to determine the molecular identity of this peak. The results of these experiments are shown in Fig. 8.

Fig. 8 shows HREEL spectra after $15 \mathrm{ML}$ lithium on HOPG at $100 \mathrm{~K}$ was exposed to $0.125 \mathrm{~L}$ of $\mathrm{D}_{2} \mathrm{O}_{(\mathrm{g})}$ and after $15 \mathrm{ML}$ lithium on HOPG at $100 \mathrm{~K}$ was exposed to $0.125 \mathrm{~L}$ of $\mathrm{H}_{2} \mathrm{O}_{(\mathrm{g})}$. As expected the peak at 3688 is shifted to $2716 \mathrm{~cm}^{-1}$, but the peak at 952 is shifted to $721 \mathrm{~cm}^{-1}$, indicating that the mode which gives rise to the peak at $952 \mathrm{~cm}^{-1}$ involves an $\mathrm{H}$ atom. Two possibilities exist as to what mode produces this peak: an $\mathrm{Li}-\mathrm{H}$ stretch or an $\mathrm{O}-\mathrm{H}$ bend from $\mathrm{LiOH}$. The $\mathrm{Li}-\mathrm{H}$ bond could have been formed during the initial reaction of $\mathrm{H}_{2} \mathrm{O}_{(\mathrm{g})}$ with lithium producing $\mathrm{LiOH}$ and $\mathrm{LiH}$. The expected frequency ratio for $v(\mathrm{Li}-\mathrm{H})$ to $v(\mathrm{Li}-\mathrm{D})$ is 1.333 . This would result in the peak at $952 \mathrm{~cm}^{-1}$ in the $\mathrm{H}_{2} \mathrm{O}$ exposed surface to be shifted down to $714 \mathrm{~cm}^{-1}$ in the $\mathrm{D}_{2} \mathrm{O}$ exposed surface if it is due to the $v(\mathrm{Li}-\mathrm{D})$ peak. This is very close to the peak's observed position of $721 \mathrm{~cm}^{-1}$. However, the frequency ratio for $\delta(\mathrm{O}-\mathrm{H})$ to $\delta(\mathrm{O}-\mathrm{D})$ is 1.375 . This would result in the peak at 952 shifting down to $692 \mathrm{~cm}^{-1}$, which is still close to the peak's actual position of $721 \mathrm{~cm}^{-1}$. Based on the observed isotopic shifts, it is likely that

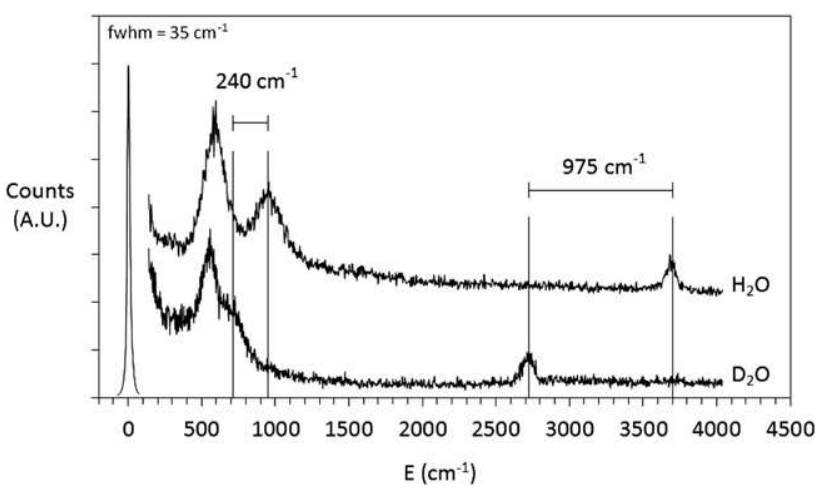

Fig. 8. An HREEL spectra of a $15 \mathrm{ML}$ lithium film on HOPG at $100 \mathrm{~K}$ exposed to $0.125 \mathrm{~L}$ $\mathrm{H}_{2} \mathrm{O}_{\text {g }}$ (top) and an HREEL spectra of a $15 \mathrm{ML}$ lithium film on HOPG at $100 \mathrm{~K}$ exposed to $0.125 \mathrm{~L} \mathrm{D}_{2} \mathrm{O}_{(\mathrm{g})}$ (bottom). Both the $\mathrm{H}_{2} \mathrm{O}_{(\mathrm{g})}$ and $\mathrm{D}_{2} \mathrm{O}_{(\mathrm{g})}$ partial pressures used during these exposures were $1 \times 10^{-8}$ Torr. The typical resolution and elastic peak intensity of the spectra was $25 \mathrm{~cm}^{-1}$ fwhm and 30,000 cts/s. this peak is the result of a $v(\mathrm{Li}-\mathrm{H})$ vibration. Unfortunately the $24 \mathrm{~cm}^{-1}$ difference between the two predicted shifts is too small to make a conclusive determination, given the resolution and signal to noise ratio of the HREEL spectra seen in Fig. 8. Thus, consideration of other related spectroscopic studies is needed to confirm the assignment of this peak.

Previous infrared vibrational spectroscopic studies of metal hydroxides have found that the $\delta(\mathrm{O}-\mathrm{H})$ of metal hydroxides typically are in the range of 190 to $650 \mathrm{~cm}^{-1}$ [20-22]. Specifically, Wang and Andrews [20] found that the $\delta(\mathrm{O}-\mathrm{H})$ for matrix isolated $\mathrm{NiOH}, \mathrm{CoOH}, \mathrm{FeOH}$, and $\mathrm{MnOH}$ were $645,450,352$, and $193 \mathrm{~cm}^{-1}$, respectively. They also found that for every metal hydroxide the $\delta(\mathrm{O}-\mathrm{H})$ was at a lower wavenumber than the metal oxygen stretch. In addition to these studies, Acquista and Abramowitz [21] performed similar work using alkali metals and found that matrix isolated $\mathrm{CsOH}, \mathrm{RbOH}$, and $\mathrm{NaOH}$ had $\delta(\mathrm{O}-\mathrm{H})$ frequencies of 302, 309, and $337 \mathrm{~cm}^{-1}$, respectively. Again, they also found that for every metal hydroxide the $\delta(\mathrm{O}-\mathrm{H})$ was at a lower frequency than the metal oxygen stretch. While there have been no matrix isolation studies of LiOH, Buchanan [22] and Yoshida and Hase [18] found, using IR spectroscopy on bulk $\mathrm{LiOH}_{(s)}$, that LiOH has a $\delta(\mathrm{O}-\mathrm{H})$ frequency of 426 and $421 \mathrm{~cm}^{-1}$, respectively. In all these infrared vibrational studies of metal hydroxides, it was found that the $\delta(\mathrm{O}-\mathrm{H})$ was at a lower frequency than the metal-oxygen stretch. The results of this work suggests that the peak at $952 \mathrm{~cm}^{-1}$ is not a result of a $\delta(\mathrm{O}-\mathrm{H})$ mode of LiOH, but most likely the result of a $v(\mathrm{Li}-\mathrm{H})$ stretching mode.

Another clue as to the nature of the peak at $952 \mathrm{~cm}^{-1}$ can be found in the intensities of the peaks in the spectra taken after $0.0625,0.125$, 0.25 and $0.50 \mathrm{~L} \mathrm{H}_{2} \mathrm{O}$ exposures, as seen in Fig. 7. At $0.0625 \mathrm{~L} \mathrm{H}_{2} \mathrm{O}_{(\mathrm{g})}$ exposure, the HREEL spectrum shows a peak at $600 \mathrm{~cm}^{-1}$, corresponding to the $\mathrm{Li}-\mathrm{OH}$ stretch and a peak at $952 \mathrm{~cm}^{-1}$, at half the intensity of the $600 \mathrm{~cm}^{-1}$ peak, and a peak at $3688 \mathrm{~cm}^{-1}$ corresponding to the $v(\mathrm{LiO}-\mathrm{H})$. As the $\mathrm{H}_{2} \mathrm{O}_{(\mathrm{g})}$ exposure increases to $0.125 \mathrm{~L}$, the $600 \mathrm{~cm}^{-1}$, $952 \mathrm{~cm}^{-1}$, and the $3688 \mathrm{~cm}^{-1}$ peaks increase in intensity proportionally with exposure, and their relative intensities remain the same. However, as the exposure increases to $0.25 \mathrm{~L}$, the peaks at 600 and $3688 \mathrm{~cm}^{-1}$ increase in intensity proportionally to the $\mathrm{H}_{2} \mathrm{O}$ exposure, but the peak at $952 \mathrm{~cm}^{-1}$ does not further increase in intensity. Its intensity remains the same as in the HREEL spectrum for $0.125 \mathrm{~L}$ exposure. This can be explained by the fact that at low $\mathrm{H}_{2} \mathrm{O}_{(\mathrm{g})}$ exposures, when much of the topmost lithium layer has not yet been oxidized to $\mathrm{LiOH}, \mathrm{H}_{2} \mathrm{O}_{(\mathrm{g})}$ reacts with lithium to form $\mathrm{LiOH}$ and $\mathrm{LiH}$. Then as $\mathrm{H}_{2} \mathrm{O}_{(\mathrm{g})}$ exposure increases up to $0.5 \mathrm{~L}$, there are no longer free lithium atoms to react with an $\mathrm{H}$ atom from an adsorbed $\mathrm{H}_{2} \mathrm{O}$ molecule preventing it from reacting to form $\mathrm{LiOH}$ and $\mathrm{LiH}$. This would also explain the passivation of the lithium film after about $0.5 \mathrm{~L}$ of $\mathrm{H}_{2} \mathrm{O}_{(\mathrm{g})}$ exposure. If this peak were the result of an $\mathrm{O}-\mathrm{H}$ bend from $\mathrm{LiOH}$, it would be expected to increase in intensity just as the peaks at 600 and $3688 \mathrm{~cm}^{-1}$ increase in intensity. Thus, again it is more likely the peak at $952 \mathrm{~cm}^{-1}$ is a result of an $\mathrm{Li}-\mathrm{H}$ stretch rather than an $\mathrm{O}-\mathrm{H}$ bend from $\mathrm{LiOH}$.

HREELS spectra where taken immediately after the AES oxygen uptake experiments for the 1,5 , and $15 \mathrm{ML}$ lithium films on HOPG at $100 \mathrm{~K}$ exposed to $15 \mathrm{~L} \mathrm{H}_{2} \mathrm{O}_{(\mathrm{g})}$. These spectra are shown in Fig. 9.

Fig. 9 shows that as the initial lithium film thickness increases, the intensity of the LiOH peaks around 600 and the peaks at $3700 \mathrm{~cm}^{-1}$ increase in intensity. This would be expected since a thicker initial lithium film should produce a thicker LiOH film. However, the $v(\mathrm{LiO}-\mathrm{H})$ at $3700 \mathrm{~cm}^{-1}$ is only discernable in the HREEL spectrum for the $15 \mathrm{ML}$ lithium surface. This could be the result of this small peak at $3700 \mathrm{~cm}^{-1}$ being obscured by the H-bonded $v(\mathrm{O}-\mathrm{H})$ produced by adsorbed $\mathrm{H}_{2} \mathrm{O}$. Additionally, it is difficult to discern a peak around $600 \mathrm{~cm}^{-1}$, corresponding to the $v(\mathrm{Li}-\mathrm{OH})$, for the spectrum recorded after oxygen uptake by a $1 \mathrm{ML}$ lithium film. As a result, it is not possible to conclude that the $1 \mathrm{ML}$ lithium film produces $\mathrm{LiOH}$ after exposure to $15 \mathrm{~L}$ of $\mathrm{H}_{2} \mathrm{O}$ during the AES oxygen uptake experiment. All three spectra show similar intensities for the peaks corresponding to adsorbed $\mathrm{H}_{2} \mathrm{O}$, which are around $220,800,1600$, and $3400 \mathrm{~cm}^{-1}$. 


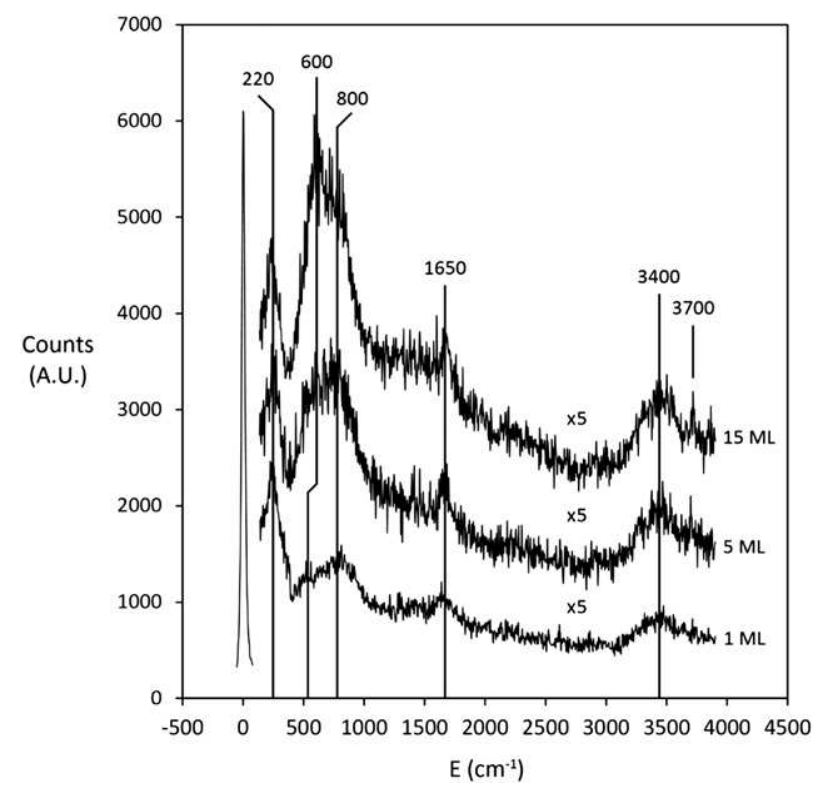

Fig. 9. HREEL spectra taken after the $15 \mathrm{~L}$ of $\mathrm{H}_{2} \mathrm{O}_{(\mathrm{g})}$ exposure from the AES oxygen uptake experiments for 1,5 , and $15 \mathrm{ML}$ lithium films on HOPG at $100 \mathrm{~K}$. The typical resolution and elastic peak intensity of the spectra was $35 \mathrm{~cm}^{-1}$ fwhm and 50,000 cts/s.

Auger spectroscopy survey scans were also recorded after the AES oxygen uptake experiments for the 1,5 , and $15 \mathrm{ML}$ lithium films on HOPG at $100 \mathrm{~K}$ exposed to $15 \mathrm{~L} \mathrm{H}_{2} \mathrm{O}_{(\mathrm{g})}$. Using Auger sensitivity factors, this data allows the calculation of the ratios of the atomic concentrations of lithium to oxygen following saturation. These ratios are presented in Table 5.

For the $1 \mathrm{ML}$ lithium film, AES survey scans show a lithium to oxygen ratio of 3 to 1. The HREEL spectrum taken after the AES oxygen uptake experiment of a $1 \mathrm{ML}$ lithium film, seen in Fig. 9 shows adsorbed $\mathrm{H}_{2} \mathrm{O}$ on the surface. This HREEL spectrum would suggest that the AES lithium to oxygen ratio of 3 to 1 is too high, since the $1 \mathrm{ML}$ lithium film HREEL spectrum in Fig. 9 shows excess oxygen in the form of physisorbed $\mathrm{H}_{2} \mathrm{O}$. However, the HREEL spectrum was taken 30 min after the AES survey scan was taken, and the $\mathrm{H}_{2} \mathrm{O}_{(\mathrm{g})}$ background gas pressure was an average of $1 \times 10^{-9}$ Torr during those $30 \mathrm{~min}$ as a result of residual $\mathrm{H}_{2} \mathrm{O}_{\text {(g) }}$ from the AES oxygen uptake experiment. This would result in an $\mathrm{H}_{2} \mathrm{O}_{(\mathrm{g})}$ exposure of approximately $2 \mathrm{~L}$ and could explain the presence of adsorbed $\mathrm{H}_{2} \mathrm{O}$ on the surface seen in the HREEL spectrum and the lithium to oxygen ratio of 3 to 1 found immediately after the $\mathrm{H}_{2} \mathrm{O}_{(\mathrm{g})}$ oxygen uptake experiment. Additionally, the lithium to oxygen ratio of 3 to 1 also provides evidence for the formation of $\mathrm{LiH}$ during the initial oxidation of the lithium film by $\mathrm{H}_{2} \mathrm{O}_{(\mathrm{g})}$. For the 5 and $15 \mathrm{ML}$ lithium films, the formation of $\mathrm{LiH}$ and the passivation of the lithium film, preventing the oxidation of the deeper lithium layers, would result in a high lithium to oxygen ratio that increases when going from initial lithium films of $5 \mathrm{ML}$ to $15 \mathrm{ML}$. These high lithium to oxygen ratios are observed in the Auger data to be 3.5 to 1 and 3.8 to 1 for the $5 \mathrm{ML}$ and the $15 \mathrm{ML}$, respectively.

Table 5

Ratios of lithium to oxygen atoms in the 1,5, and $15 \mathrm{ML}$ lithium films on HOPG at $100 \mathrm{~K}$ after the $15 \mathrm{~L}$ of $\mathrm{H}_{2} \mathrm{O}_{(\mathrm{g})}$ exposure from the AES oxygen uptake experiments.

\begin{tabular}{cll}
\hline Atomic conc. & $\mathrm{Li}$ & $\mathrm{O}$ \\
\hline $1 \mathrm{ML} \mathrm{Li}$ & 3.0 & 1.0 \\
$5 \mathrm{ML} \mathrm{Li}$ & 3.5 & 1.0 \\
$15 \mathrm{ML} \mathrm{Li}$ & 3.8 & 1.0 \\
\hline
\end{tabular}

\section{Conclusions}

The oxidation of lithium thin films on $\mathrm{HOPG}$ by $\mathrm{O}_{2(\mathrm{~g})}$ and $\mathrm{H}_{2} \mathrm{O}_{(\mathrm{g})}$ has been studied using AES and HREELS. The AES oxygen uptake experiments have shown that as the initial lithium film thickness on HOPG decreased from 15 to 5 to $1 \mathrm{ML}$, the rate of oxidation by $\mathrm{O}_{2(\mathrm{~g})}$ decreased. AES measurements also showed that a $15 \mathrm{ML}$ lithium film was fully oxidized by $\mathrm{O}_{2(\mathrm{~g})}$ after $9.7 \mathrm{~L}$ of $\mathrm{O}_{2(\mathrm{~g})}$ exposure. HREEL spectra showed that the $15 \mathrm{ML}$ lithium film exhibited peaks that were characteristic of $\mathrm{Li}_{2} \mathrm{O}$, and as the initial lithium film thickness on HOPG increased from 1 to 5 to $15 \mathrm{ML}$, the HREEL peak positions moved closer to the positions expected by the formation of $\mathrm{Li}_{2} \mathrm{O}$. Additionally, HREEL spectra showed that, even at $100 \mathrm{~K}$ and low exposures $(<0.5 \mathrm{~L}), \mathrm{O}_{2(\mathrm{~g})}$ fully dissociated upon reacting with the lithium thin films.

AES oxygen uptake experiments have shown that as the initial lithium film thickness decreased from 15 to 5 to $1 \mathrm{ML}$, the rate of oxidation by $\mathrm{H}_{2} \mathrm{O}_{(\mathrm{g})}$ decreased. However, this effect was less pronounced for

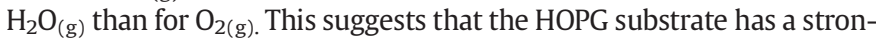
ger effect on the oxidation of the lithium thin films by $\mathrm{O}_{2(\mathrm{~g})}$ than by $\mathrm{H}_{2} \mathrm{O}_{(\mathrm{g})}$. AES measurements also showed that the $15 \mathrm{ML}$ lithium film did not fully oxidize after $15 \mathrm{~L}$ of $\mathrm{H}_{2} \mathrm{O}_{(\mathrm{g})}$ exposure, but the 5 and $1 \mathrm{ML}$ lithium films did fully oxidize. HREEL spectra showed that the lithium thin film initially reacted with $\mathrm{H}_{2} \mathrm{O}_{(\mathrm{g})}$ to form lithium hydride and lithium hydroxide, but after $0.5 \mathrm{~L}$ of $\mathrm{H}_{2} \mathrm{O}_{(\mathrm{g})}$ exposure, $\mathrm{H}_{2} \mathrm{O}_{(\mathrm{g})}$ began to physisorb on the lithium surface.

These results demonstrate how a graphite substrate can affect the rate of oxidation of lithium thin films, and what products were formed during oxidation of lithium thin films by $\mathrm{O}_{2(\mathrm{~g})}$ and $\mathrm{H}_{2} \mathrm{O}_{(\mathrm{g})}$. This work has provided insight into the initial oxidation processes of lithiated graphite products, which are used in first wall materials for thermonuclear fusion reactors, and also in lithium battery applications [23]. Additionally, the HREELS studies of the initial oxidation of lithium thin films by $\mathrm{H}_{2} \mathrm{O}_{(\mathrm{g})}$ have provided a unique insight into the dissociation mechanism of $\mathrm{H}_{2} \mathrm{O}_{(\mathrm{g})}$ on a lithium surface by showing vibrational evidence for the formation of lithium hydride along with lithium hydroxide surface species.

\section{Acknowledgements}

This work was supported by the Department of Energy, Office of Fusion Energy Sciences, under award \#DE-SC0008598. Partial support for SMW by the Program in Plasma Science of the Princeton Plasma Physics Laboratory is also acknowledged

\section{References}

[1] G. Federici, et al., Nucl. Fusion 41 (2001) 1968.

[2] D.K. Mansfield, et al., Nucl. Fusion 41 (2001) 1823.

[3] C.N. Taylor, B. Heim, J.P. Allain, J. Appl. Phys. 109 (2011) 53306.

[4] C.H. Skinner, R. Sullenberger, B.E. Koel, M.A. Jaworski, H.W. Kugel, J. Nucl. Mater. 438 (2013) S647.

[5] K.R. Zavadil, N.R. Armstong, Surf. Sci. 230 (1989) 47.

[6] J.R. Hoenigmann, R.G. Keil, Appl. Surf. Sci. 18 (1984) 207.

[7] SEAS Getters, Alkali Metal Dispensers, 2007 Retrieved from https://www.saesgetters. $\mathrm{com} / \mathrm{sites} /$ default/files/AMD\%20Brochure_0.pdf (2015).

[8] N. Itou, et al., J. Nucl. Mater. 290-293 (2001) 281.

[9] L.E. Davis, N.C. Macdonald, P.W. Palmberg, G.E. Riach, R.E. Weber, Handbook of Auger Spectroscopy, second ed. Perkin-Elmer Corp., Physical Electronics Division, Eden Prairie, 1978.

[10] RBD Instruments, AugerScan Software.

[11] A.R. DuCharme, R.L. Gerlach, J. Vac. Sci. Technol. 11 (1974) 281.

[12] W. Reuter, in: G. Shinoda, K. Kohra, T. Ichinokawa (Eds.), Proc. 6th Intern. Conf. on X-Ray Optics and Microanalysis, University of Tokyo Press 1972, p. 121.

[13] M. Succi, R. Canino, B. Ferrario, Vacuum 35 (1985) 579

[14] R.E. Clausing, Surf. Sci. 36 (1973) 377.

[15] G. Hanke, K. Muller, Surf. Sci. 152/153 (1985) 902. 
[16] C.J. Powell, A. Jablonski, NIST Electron Inelastic-Mean-Free-Path Database - Version 1.2, National Institute of Standards and Technology, Gaithersburg, MD, 2010 (M.T.). [17] M.T. Johnson, H.I. Starnberg, H.P. Hughes, Surf. Sci. 178 (1986) 290.

[18] L. Vaska, Acc. Chem. Res. 9 (1976) 175.

[19] C.J. Cramer, W.B. Tolman, K.H. Theopold, A.L. Rheingold, PNAS 100 (2003) 3635.
[20] T. Osaka, I. Shindo, Solid State Commun. 51 (1984) 421.

[21] I.V.P. Yoshida, Y. Hase, Spectrosc. Lett. 12 (1979) 409.

[22] D.V. Chakarov, L. Österlund, B. Kasemo, Vacuum 46 (8-10) (1995) 1109

[23] X. Wang, L. Andrews, J. Phys. Chem. A 110 (2006) 10035. 